\title{
The Hamiltonian view of social evolution
}

\author{
Review essay of \\ The Philosophy of Social Evolution, Jonathan Birch. Oxford University Press, Oxford (2017).
}

224 pp., Hardcover, ISBN: 9780198733058

\author{
J. Arvid Ågren \\ Department of Molecular Biology and Genetics, Cornell University \\ 227 Biotechnology Building, Ithaca, NY, 14853 \\ ja495@cornell.edu
}

April 18, 2018 


\section{Introduction}

In the obituary of her mentor Bill Hamilton, the American entomologist and evolutionary biologist Marlene Zuk wrote that the difference between Hamilton and everyone else was "not the quality of his ideas, but their sheer abundance" (Zuk 2000). The proportion of his ideas that were actually good was about the same as anyone else, "the difference between Bill and most other people was that he had a total of over one hundred ideas, with the result that at least ten of them were brilliant, whereas the rest of us have only four or five ideas as long as we live, with the result that none of them are". Hamilton indeed had many good ideas. Over the years he made substantial contributions to the study of the origin of sex, genetic conflicts, and the evolution of senescence (Ågren 2013). His best idea, and the one that bears his name, is about the evolution of social behaviour, especially altruism. Hamilton's Rule, and the related concepts of inclusive fitness and kin selection, have been the bedrock of the study of social evolution for the past half century (Figure 1).

Jonathan Birch's recent book The Philosophy of Social of Evolution is a superb exploration of philosophical implications of Hamilton's work. The philosophy of biology has a long-standing close relationship with evolutionary biology (maybe too close some have argued (Pradeu 2017)). Within evolutionary biology, the study of social evolution has been especially important. In a recent interview (Marshall 2016), Elliot Sober, one of the founders of the field, described how he to came to the philosophy of biology after being intrigued by William Wimsatt's review of George C. Williams's classic critique of group selection Adaptation and Natural Selection (Williams 1966; Wimsatt 1970). Pioneering books in the field of philosophy of biology, like Sober's The Nature of Selection (Sober 1984), Elizabeth Lloyd's The Structure and Confirmation of Evolutionary Theory (Lloyd 1988), and Daniel Dennett's Darwin's Dangerous Idea (Dennett 1995) all dedicated large chunks to the issues 
of causality, altruism and selfishness, and the levels of selection, raised by influential books on social evolution, especially Williams' Adaptation and Natural Selection and Richard Dawkins' The Selfish Gene (Dawkins 1976). These authors belong to the finest tradition in the philosophy of science. They are deeply informed about the biology in question and their work contributed to the advancement of not only to philosophy of biology but to its practice as well. Early on in The Philosophy of Social Evolution (p. 9), Birch aligns his book to this tradition, to which Brandon (1990), Okasha (2006), and Godfrey-Smith (2009) also belong, and in my view the book fits squarely in that company.

In The Philosophy of Social Evolution Birch provides a comprehensive introduction to the conceptual foundations of the Hamiltonian view of social evolution, and a passionate defence of its enduring value in face of the recent high profile criticism. The book is divided into two parts: Foundations (five chapters) and Extensions (three chapters). The early parts lay out the Hamiltonian approach to social evolution. In particular, Birch takes his starting point in David Queller's formulation of Hamilton's Rule (Queller 1992), dubbed Hamilton's Rule General (HRG), and this version is central to the arguments throughout the book. In this review essay, I will therefore first outline HRG and its derivation. With this in place, I will then navigate through the often quite fierce disagreements that Hamilton's Rule, including HRG, generates and evaluate Birch's central argument of the book that HRG serves as an organizing framework for social evolution research under which we can compare and interpret more detailed causal models. The book also contains novel insights on group vs. kin selection models, conceptions of social fitness, and recent developments in the study of the origin of multicellularity and cultural evolution. These chapters are all stimulating, but in the interest of space I will spend the remainder of the review on what I take to be three of the most exciting implications of Hamilton's thinking raised by Birch: (1) the extension of 
Hamilton's Rule to mobile genetic elements, (2) maximization of inclusive fitness models and the idea of adaptation as organism design, and (3) the relationship between Hamilton's approaches to social behaviour and the gene's-eye view of evolution.

\section{Defining Hamilton's Rule}

One of the most famous anecdotes in evolutionary biology involves the Orange Tree pub, once located around the corner from the University College London at the intersection of Gower Street and Euston Road ${ }^{1}$. In it, some time in the 1950s, JBS Haldane is meant to have proclaimed (after "calculating on the back of an envelope for some minutes") to his graduate student John Maynard Smith that "he was prepared to lay down his life for eight cousins or two brothers" (Maynard Smith 1975). This quip is often used to summarize the essence of our modern understanding of social evolution: costly social behaviour (altruism) can evolve if it is preferentially directed towards relatives. Independently of Haldane, Hamilton formalized this insight in two papers: a short note in The American Naturalist in 1963 and then a majestic two-part paper in The Journal of Theoretical Biology the following year (Hamilton 1963, 1964). And while Maynard Smith would be instrumental in getting the 1964 paper published, their relationship never really recovered from what Hamilton considered a gross oversight by Maynard Smith in repeatedly attributing the basic insight to Haldane (Segerstrale 2013).

The current controversy over Hamilton's Rule can be illustrated by contrasting two quotes from leading authors on each side of the debate. One the one hand, in the paper that kicked it all off, Nowak et al. (2010) write that Hamilton's Rule "almost never holds". On the

\footnotetext{
${ }^{1}$ In a fantastic piece of detective work, Birch reveals that after the Orange Tree was demolished in 1963, the rubble was used for the photo on the cover of the Beatles' EP Twist and Shout.
} 
other, Gardner et al. (2011) describe the Nowak et al. statement as "simply incorrect" and go on to argue that Hamilton's Rule has “the same generality and explanatory power as the theory of natural selection itself'. More recently, the skeptical attitude is clearly laid out in van Veelen et al. (2017), and the enthusiastic case receives a book-length treatment in Marshall (2015).

While the informal version of Hamilton's Rule $(r b>c$; Figure 1) will make an appearance in most introductory evolution courses, the version subject to current debate takes a bit more getting used to. Birch's introduction to this version, David Queller's (1992) 'general model' referred to as 'HRG', is very instructive. In particular, it does an excellent job highlighting the key assumptions that make HRG simultaneously so attractive for its supporters and so unbearable for its critics. The following passage outlining the HRG derivation will therefore largely follow Birch's lead.

Queller's derivation of Hamilton's Rule takes its starting point in the Price equation (Price 1970; Frank 2012). The Price equation is a simple abstract statement about evolutionary change from one generation to the next, such that

$$
\Delta \bar{p}=\frac{1}{w}\left[\operatorname{Cov}\left(w_{i}, p_{i}\right)+E\left(w_{i} \Delta p_{i}\right)\right](1)
$$

The change in population frequency of a given allele $(\Delta \bar{p})$, where $p_{i}$ is the individual gene frequency of the $i^{\text {ith }}$ individual for the allele under consideration, is the sum of two population statistics. The first is the selection term, given by $\operatorname{Cov}\left(w_{i}, p_{i}\right)$, the covariance between individual fitness $\left(w_{i}\right)$ and individual gene frequency $\left(p_{i}\right)$, and the second is the transmission term, $E\left(w_{i} \Delta p_{i}\right)$, the expected change in $p_{i}$ between parent and offspring. They are both weighed by the population mean fitness $\bar{w}$. With this in place, Birch outlines the three key assumptions made by Queller in deriving HRG from the Price equation. 
First, $p_{i}$ is reinterpreted as a breeding value, as used in quantitative genetics. This is possible because $p_{i}$ can be thought of as not just an individual gene frequency, but as a linear combination of frequencies across multiple alleles of multiple loci. From this, $\Delta \bar{p}$ becomes the change in a quantitative polygenic trait. Next, the transmission term $E\left(w_{i} \Delta p_{i}\right)$ is assumed to be 0 . This has two biological implications. Number one is that processes like segregation distortion, gametic selection, and genetic drift are assumed be negligible. Number two is that the average effects of alleles on the considered phenotype are constant. Because dominance and epistasis can both cause this assumption to be violated, one way to conceptualize it is to think of the 'genic environment' being held fixed. (An assumption one might recognize from discussions of Fisher's (Fisher 1930) fundamental theorem of natural selection (Okasha 2008; Ewens 2010).) Both assumptions are quite substantial and I will return to them later in the review. Finally, with $E\left(w_{i} \Delta p_{i}\right)$ dropped, $\operatorname{Cov}\left(w_{i}, p_{i}\right)$ is conceived as the effect of natural selection on the evolutionary change of the trait under study and we are left with

$$
\Delta \bar{p}=\frac{1}{w}\left[\operatorname{Cov}\left(w_{i}, p_{i}\right)\right](2)
$$

To get from this to the familiar $r b>c$, the selective covariance term must be partitioned into $r b$ and $c$. Queller achieved this by making use of the Lande-Arnold regression model of fitness (Lande and Arnold 1983) and therefore first stating the fitness of the of the $i^{\text {ith }}$ individual using a linear regression model, such that

$$
w_{i}=\alpha+\beta_{1} p_{i}+\beta_{2} \widehat{p}_{i}+\varepsilon_{w_{i}}(3)
$$

The linear function considers the gene frequency of a given individual $\left(p_{i}\right)$, as well as the average individual gene frequency of its social partners $\left(\widehat{p}_{i}\right)$. It then captures the partial regression of an individual's fitness on that individual's gene frequency $\left(\beta_{i}\right)$, accounting for the that of the social partners' and the partial regression of an individual's fitness on the gene 
frequency of social partners', this time accounting for that individual's gene frequency. $\alpha$ is the non-social part of fitness and taken to be the same for all individuals. $\varepsilon_{w_{i}}$ is the traditional error term of linear regressions, here it represents the discrepancy between actual and predicted fitness of the $i^{\text {ith }}$ individual. This regression model is then substituted into the Price equation (2), leading to

$$
\bar{w} \Delta \bar{p}=\operatorname{Cov}\left(\alpha, p_{i}\right)+\beta_{1} \operatorname{Var}\left(p_{i}\right)+\beta_{2} \operatorname{Cov}\left(\widehat{p}_{i}, p_{i}\right)+\operatorname{Cov}\left(\varepsilon_{w_{i}}, p_{i}\right)
$$

Simplifying and rearranging to state the condition for the population mean of the trait of interest to increase $(\Delta \bar{p})>0$ gives

$$
\Delta \bar{p}>0 \Leftrightarrow \frac{\operatorname{Cov}\left(\widehat{P}_{i}, p_{i}\right)}{\operatorname{Var}\left(p_{i}\right)} \beta_{2}>-\beta_{1}
$$

Then, because $r, b, c$, in Hamilton's Rule can be defined as

$$
r=\frac{\operatorname{Cov}\left(\widehat{p}_{i}, p_{i}\right)}{\operatorname{Var}\left(p_{i}\right)}, b=\beta_{2}, \text { and } c=-\beta_{1}
$$

this notation means that (5) can be rewritten as

$$
(\Delta \bar{p})>0 \Leftrightarrow r b>c(\mathrm{HRG})
$$

This is the formulation of Hamilton's Rule that Birch, following a previous paper of his (Birch 2014b), calls Hamilton's Rule General (HRG).

At this point, it is worth pausing and reflecting on what the variables in HRG actually mean. Because there is no such thing as a regression coefficient for a single data point, $r, b$, and $c$ are not actually properties of individual organisms or of any given social interaction (which for example a first look at Figure 1 may have you believe). Instead, they are population statistics: $r$ is the slope of the line of best fit plotting $\widehat{p}_{i}$ against $p_{i}$ for every individual in the population, and $b$ and $c$ can be calculated from the plane of best fit after adding $w_{i}$ to the $\widehat{p}_{i}$ against $p_{i}$ plot. This formulation may at first seem strange, but it leads to a flexibility that can be a great strength, or a great weakness depending on who you ask. 


\section{Hamilton's Rule as an organizing framework in social evolution}

The heart of Birch's defence of the Hamiltonian approach to social evolution is the proposition that HRG can act as an organizing framework that allows us to identify common mechanisms in the origin of social behaviours. It offers a classificatory scheme and common vocabulary to translate between models, which means that more detailed theoretical models can be interpreted, compared, and contrasted in a unified way (Figure 2).

Hamilton's Rule, however, has been subject to plenty of criticism. As I shall argue, HRG as an organizing framework provides good counter-arguments to these criticisms, though lands no knock-out punches. The criticisms can be divided into three broad themes: HRG is tautological, it makes no predictions, and it fails to generate causal explanations. Crucial to all arguments are the minimal assumptions of HRG. In fact, in a recent articulation of this criticism, Allen et al. (2013) go so far as claiming that it requires no assumptions. Birch argues that this is not true and the omission of $E\left(w_{i} \Delta p_{i}\right)$ in HRG is a substantial one. Because of phenomena such as selfish genetic genetic transmission will be biased more often than many biologists probably appreciate, and $E\left(w_{i} \Delta p_{i}\right)$ will thus not equal 0 , he is some ways correct, and I will return to my own issues with this assumption. On the other hand, the importance of selfish genetic elements is hardly at the heart of the disagreement between proponents and critics of $\mathrm{HRG}$, so the relevance of this particular defence of $\mathrm{HRG}$ is somewhat limited. Nevertheless, any model is only is only ever as good as its assumptions (garbage in, garbage out, to be crass), and one can argue that because the assumptions of HRG are so minimal, so are the scientific insights that can be gained from it. This is a fair point. Indeed, HRG will be of little help in predicting evolutionary change in a given ecological situation. Similarly, because regression coefficients are used to define the parameters, it can only ever identify correlations not actual causations. 
Birch's reply, with which I am inclined to agree, is to concede several of these points (I would also concede that some defences of HRG have been characterized by hyperbolic claims about generality), but also to point that these criticisms measure the value of HRG against the wrong yard-stick. The point of HRG is not to provide exact fine grained causal explanations of particular scenarios, but instead offers a way to classify, compare, and contrast more detailed causally appropriate models. For example, while the mathematical details of, for example, Axelrod and Hamilton's game theoretical "tit-for-tat"-models (Axelrod and Hamilton 1981) and Taylor and Frank's (1996) kin selection differential equations are quite different, they can be can be translated into the HRG framework and shown to satisfy the $r b>c$ inequality. It is worth highlighting that in these comparisons $r, b$, and $c$, are no longer meaningful separate entities. Instead, what matters is the $c$ and the compound parameter $r b$. Should this be called Hamilton's Rule? Would it not be more accurate to rename $r b$ as a single, rather than a compound, parameter? One might say that still calling this Hamilton's Rule, despite the intuitive notions of cost and benefit no longer residing in the parameters $b$ and $\mathrm{c}$, is an artificial attempt to keep an old notation that is no longer relevant. Whatever we call it (I personally do not see keeping the old notation as unproductive nostalgia), HRG does makes it possible to see biological phenomena as disparate as limited dispersal, shared habitat preferences, kin recognition, greenbeards, and horizontal gene transfer, as common mechanisms that can generate a positive genetic correlation between actor and recipient of a given social behaviour. Similarly, punishment, reciprocity, linkage, and pleiotropy are all mechanisms that link a behaviour that is costly in the short-term, with a long-term direct fitness benefit. This kind of unification is no way a trivial achievement. 
It is perhaps also worth noting mathematical frameworks that themselves make no predictions, but facilitate comparisons between more specific models are no way unique to social evolution. For example, this is the case also in physics, as recently expressed by Nobel Prize winner Steven Weinberg:

“Our most important theories, like Newtonian mechanics and quantum mechanics, are not falsifiable, because they do not make predictions by themselves, but provide general frameworks for more specific theories, which do make predictions" (Horgan 2015)

What, then, is purpose of mathematical models in evolutionary biology? If different models make the same empirical prediction, can, as John Maynard Smith once put it (1987), any good Popperian consider the matter of choosing between models as anything other than pseudoscience? I do think there is a serious discussion to be had about different modeling traditions in evolutionary biology (Servedio et al. 2014), not just whether we prefer one framework over another, but also why. In a commentary to a paper by Peter Godfrey-Smith and Benjamin Kerr that compared contextual and collective approaches to modeling multilevel selection (Kerr and Godfrey-Smith 2002), the same Maynard Smith (2002) prefaced his criticisms by admitting that his gene-centred views "may merely reflect the fact that I prefer microscopic to holistic models: Maxwell-Boltzmann to classical thermodynamics, and Dawkins to Price's equation." That kind of honest philosophical transparency is exactly what we need more of in evolutionary biology.

\section{Hamilton's Rule and mobile genetic elements}

In the first volume of his collected papers, Narrow Roads of Gene Land, Hamilton reflected on the inevitability of genomic conflicts: 
"Seemingly inescapable conflict within diploid organisms came to me as both a new agonizing challenge and at the same time as a release from a personal problem I had had all my life (...) Given my realization of an eternal disquiet within, couldn't I feel better about my own inability to be consistent in what I was doing, about indecision in matters ranging from daily trivialities up to the very nature of right and wrong? (...) As I write these words, even as to be able to write them, I am pretending to a unity that, deep inside myself, I now know does not exist. I am fundamentally mixed, male with female, parent with offspring, warring segments of chromosomes..." (Hamilton 1996, 134-135)

That organisms are characterized by an "eternal disquiet within" is also a major theme of the thriving 'major transitions' research programme, which seeks common principles across the hierarchy of life, from genes to cells and organisms (Maynard Smith and Szathmáry 1995; Bourke 2011; Ågren 2014). Furthermore, the discovery that cooperation and other social behaviours are not restricted to large multicellular organisms, but are a defining feature of microbial life has not only added a new treasure trove of empirical data for the study of social evolution, but also has implications for our theoretical models. In particular, can the traditional models that were typically developed with animals in mind handle the unique biological features of selfish genetic elements, cancer cells, and social microbes? If not, what modifications need to be made?

In a stimulating chapter, Birch picks up on one of these features, the occurrence of within-species horizontal gene transfer (“gene mobility") among microbes. This kind of transfer is the source of a novel kind of genetic similarity between individuals. What, then, happens to relatedness $(r)$ in light of this? Because relatedness is not defined in terms of traditional genealogical kinship, but as the statistical correlation at a given locus between 
actor and recipient of social behaviour, the current regression based models can be said to handle it rather well already. At the same time, horizontal gene movements violate the assumption that relatedness is constant across the life cycle. Birch constructs a version of HRG that accommodates gene mobility, which he calls Hamilton's Rule Mobile (HRM). One subtle effect of this formulation is that relatedness because of horizontal transfer $\left(r_{m}\right)$ describes the statistical association at two points in time. The genic value of the actor is taken before the social act (here, as is typical in models of microbial social behaviour, production of a common good) and for the recipient it is taken after. As Birch points out, this kind of conceptualization may initially seem odd, but is easy to get your head around using a gene's-eye view. What matters for the fitness of a mobile genetic element is the fitness benefit of future carriers of it, regardless of whether those individuals are presently carrying it. I will return to the issue of individual contra gene-centred approaches to social evolution in the last section of this review.

Overall, this chapter, and the corresponding paper (Birch 2014a), is a fine contribution not only to the philosophy of biology, but also to the science of biology. It is philosophy of biology at its best. An ambitious extension of this work would be to incorporate other kinds of mobile genetic elements, such as transposable elements and the simple replicators of the RNA world, both which have been examined independently in the context of social evolution models, but rarely together (Ågren 2016a).

\section{Maximization of inclusive fitness and adaptation as organism design}

Some of the most prolific of Hamilton's current defenders take the question of complex adaptation, the appearance of organisms as if they were designed, to be the central question of evolutionary biology (Kohn 2004; Gardner 2009; Grafen 2014). I am in many ways 
sympathetic to this tendency. There really is something special about organisms. Subject to all known laws of physics, they are nonetheless different from any other physical entity. Organisms are what make biology unique as a distinct autonomous scientific discipline and the most striking feature of organisms is that they appear designed to thrive in their respective environments. What, then, should organisms appear to be maximized for? To many Hamilton supporters the answer is to maximize inclusive fitness (this view is most clearly articulated by West and Gardner 2013). The formal foundation for this claim rests on Alan Grafen's ambitious Formal Darwinism Projet (Grafen 2014; Grafen 2007), which seeks to establish a formal mathematical link between the process of natural selection (captured by a version of the Price equation) and phenotypic optimality (captured by the mathematics of optimization programmes).

Like Birch, I find much to admire in the Formal Darwinism Project, but ultimately remain skeptical of the claim that we should expect to find organisms adapted to maximize inclusive fitness in natural populations. There are both theoretical and empirical reasons for this. Inclusive fitness theory typically makes assumptions about the additivity as well as actor control of fitness effects, such that each fitness effect can be attributed to a single actor to which its inclusive fitness contributes. Nowak et al. (2010) and Allen et al. (2013) consider these assumptions to be so restrictive as to render the whole enterprise useless. Birch in contrast argues that the further commitment of inclusive fitness theorists to a Fisherian 'micromutationist' picture of how complex adaptations arise (more formally referred to as $\delta$-weak selection (Wild and Traulsen 2007)) can offer a way out. I do not have a strong view on this issue, one way or the other. More damning to me is the assumption of perfect genetic transmission, i.e. fair meiosis such that $E\left(w_{i} \Delta p_{i}\right)=0$ and so no role for segregation distorters and other kinds of selfish genetic elements. Gardner and Grafen (2009) put it as follows: 
"Mendelian outlaws are the exception rather than the rule, at least insofar as we are interested in understanding phenotypic evolution". I find this assumption hard to sustain in light of the sheer abundance of within-organisms conflict, not just from selfish genetic elements and other kinds of genomic conflicts (Burt and Trivers 2006), but also from selfish cell lineages such as cancer. These kinds of conflict are not just a curiosity with little evolutionary significance, but exactly what the fact that organisms are the product of major transitions in individuality teaches us to expect. As a consequence, I am, as I have argued before (Ågren 2016b), more fond of viewing organisms as adaptive compromises (Haig 2014), the product of multiple competing fitness interests, and whose very existence is a paradox (Dawkins 1990). Taken together, while I agree that adaptation and the appearance of design deserve their central roles in evolutionary biology, its current formulation of seeing organisms as inclusive fitness maximizers requires us to ignore too much interesting biology.

\section{Hamilton and the gene's-eye view of evolution}

A chief insight of the Hamiltonian approach to social evolution is that individual organisms can affect the transmission of their genes both through personal reproductive success, but also through the success of close relatives (direct vs. indirect fitness; Figure 2). Inclusive fitness provides a way to view this process from the perspective of the individual organism, but it can also be seen from a gene's-eye view (Dawkins 1976). Indeed, Hamilton himself sometimes used this perspective. In his very first paper, the 1963 note in the American Naturalist he writes:

"Despite the principle of 'survival of the fittest' the ultimate criterion that determines whether [a gene for altruism] $\mathrm{G}$ will spread is not whether the behavior is to the benefit of the behaver but whether it is of benefit to the gene G.” (Hamilton 1963) 
The equivalence of gene's-eye view and inclusive fitness has been stressed by for example Richard Dawkins who opened The Extended Phenotype (1982) with the necker cube as analogy to argue that both perspectives amount to the same thing (Table 1) .

Table 1 The equivalence claim of gene's-eye view and inclusive fitness. From Dawkins (2015, p. 318)

\begin{tabular}{|l|l|l|}
\hline Unit of selection & Role & Quantity maximized \\
\hline Gene & Replicator & Survival \\
\hline Individual organism & Vehicle & Inclusive fitness \\
\hline
\end{tabular}

Yet, the relationship between inclusive fitness and the gene's-eye is far from straightforward. Birch's discussion of Gardner's (2011) model of kin selection under blending inheritance highlights one interesting snag, and I would like to add a few more. In his fun 2011 paper, Gardner showed that one can derive HRG without assuming particular inheritance (blending inheritance complicates the computation of relatedness coefficients, but does not make it impossible). He then argues that the relationship between inclusive fitness and the gene's-eye view is more for historical reasons, than conceptual connectivity. However, as Birch notes and as outlined above, the justification of dropping $E\left(w_{i} \Delta p_{i}\right)$ in the derivation of HRG is that focusing on $\operatorname{Cov}\left(w_{i}, p_{i}\right)$ allows us to describe the natural selection part of evolutionary change in a constant environment. This assumption requires us to think of the environment of a given allele to include not just the external environment but also the rest of the genome. The idea of the genomic environment may seem strange to some, but has a long tradition stretching back all the way to Fisher (Fisher 1930), arguably the original father of the gene's-eye view (Edwards 2014). Thus, the formal connection between inclusive fitness and 
the gene's-eye may only come through a subtle point in the derivation of HRG, but is not just a historical accident.

To this snag, I would add the ambivalent attitudes of some of the key players in the popularization and criticism of the ideas, including Hamilton himself. On the one hand, Hamilton was very willing to publicly go to bat for the gene's-eye view. He wrote a very enthusiastic review of The Selfish Gene for Science and in a letter to the editor vehemently protested Richard Lewontin's critical review for Nature of the same book (Lewontin 1977), calling it a disgrace and comparing Lewontin to Bishop Wilberforce (Hamilton 1977). On the other hand, he seem to have remained committed to the individual centred inclusive fitness concept over the gene's-eye view. In the first few pages of his comprehensive 1972 review on altruism in social insects, he initially introduces his ideas using a gene-eye's view, but then proclaims "we can now abandon the fanciful viewpoint of individual genes" (p. 196) and relies for the majority of the paper on individual centered explanations (Hamilton 1972).

The failure to fully commit to his own conceptual revolution frustrated some of his biggest supporters. Both Richard Dawkins and John Maynard Smith considered inclusive fitness a sound concept, but unnecessarily messy and prone to cause misunderstandings. Indeed, both thought that Hamilton introduced the concept to save the individual as the central player of evolution, and so did not follow through on his own logic and embrace the gene's-eye view. In the second volume of his autobiography, Richard Dawkins in characteristic prose described inclusive fitness as a "regrettably cumbersome bending over backwards to rescue the individual as the focus of our Darwinian attention instead of the gene" $(2015,319)$. John Maynard Smith, equally characteristically, simply called it "an absolute swine to calculate" (Maynard Smith 1997). 
The complaint that inclusive fitness is unnecessarily complicated, prone to misunderstanding, and that one should just focus on whether an allele with a given effect on social behaviour will invade the population reminds me of some of the Nowak et al. (2010) criticism. Maybe, if their paper had included a nod to their historical predecessors, the response would not have been so heated. Part of the problem could be that there appears to be some confusion among the authors of Nowak et al. (2010) whether their model is a critique of a gene's-eye view or not. For example, in an interview with the British broadsheet The Guardian, Wilson said of selfish gene thinking:

"I have abandoned it and I think most serious scientist working on it have abandoned it. Some defenders may be out there, but they have been relatively or completely silenced since our major paper [JA ̊: Nowak et al. 2010] came out" (Johnston 2014)

At the same time, they write in the 2010 paper:

“A 'gene-centered' approach for the evolution of eusociality makes inclusive fitness theory unnecessary." (Box 1, p. 1061).

This is point is reiterated in a statement at Harvard's Program for Evolutionary Dynamics website signed by all three authors:

"our model for the evolution of eusociality is not a group selection model; instead it describes selection operating at the level of genes." (Martin A. Nowak, Corina E. Tarnita, Edward O. Wilson 2011) Mapping the conceptual and historical relationship between different verbal and formal frameworks is not just an esoteric exercise, but is crucial for our understanding of evolution. Depending on how you view the world, different phenomena will stand out. Ultimately, though my own preferences are for a gene's-eye view heuristic, coupled with a simple 
population genetic model to show that the logic holds, I see great value in everything from game theory to more sophisticated population genetics. The models of Hamilton and those of this critics may carve up evolution and natural selection in different way, but both have and will continue to help us decipher the causes of social evolution.

\section{Conclusion}

In the introductory essay to the $50^{\text {th }}$ anniversary edition of Thomas Kuhn's The Structure of Scientific Revolutions, Ian Hacking describes biology as having replaced physics as science's “top dog". Physics used to have a very productive relationship with philosophy (Schilpp 2001), but has in recent years been characterized by high profile public animosity, perhaps best exemplified by the declaration by Stephen Hawking that "philosophy is dead" (Hawking and Mlodinow 2010) and the ill-tempered exchange between David Albert (Albert 2012) and Lawrence Krauss (Krauss 2012a) over the latter's book A Universe from Nothing (Krauss $2012 b)$. The $21^{\text {st }}$ century may well belong to the life sciences, in the same way the $20^{\text {th }}$ is said to have been the century of physics. Luckily, contemporary evolutionary biology has a productive relationship with philosophy and in The Philosophy of Social Evolution Birch shows why philosophy will continue to be an integral part of the future of the study of social evolution.

\section{Acknowledgements}

I thank Ellen Clarke for the invitation to write this review, and Andrew G. Clark and Carl Veller for comments and discussion on an earlier draft. I am supported by a fellowship from the Sweden-America Foundation. 


\section{References}

Ågren, J. Arvid. 2013. “Sex, Spite, and Selfish Genes.” Journal of Genetics 92 (2): 341-43.

- 2014. "Evolutionary Transitions in Individuality: Insights from Transposable Elements." Trends in Ecology \& Evolution 29 (2): 90-96.

_. 2016a. "The Social Life of the Genome." Trends in Ecology \& Evolution 31 (7): 494-95.

- 2016b. "Selfish Genetic Elements and the Gene's-Eye View of Evolution." Current Zoology 62 (6): 659-65.

Albert, David. 2012. "On the Origin of Everything.” The New York Times, 20.

Allen, Benjamin, Martin A. Nowak, and Edward O. Wilson. 2013. "Limitations of Inclusive Fitness." Proceedings of the National Academy of Sciences of the United States of America 110 (50): 20135-39.

Axelrod, R., and W. D. Hamilton. 1981. "The Evolution of Cooperation.” Science 211 (4489): 1390-96.

Birch, Jonathan. 2014a. "Gene Mobility and the Concept of Relatedness." Biology \& Philosophy 29 (4): 445-76.

_. 2014b. "Hamilton's Rule and Its Discontents." The British Journal for the Philosophy of Science 65 (2): 381-411.

- 2017. The Philosophy of Social Evolution. Oxford: Oxford University Press.

Bourke, Andrew F. G. 2011. Principles of Social Evolution. Oxford University Press.

Brandon, Robert N. 1990. Adaptation and Environment. Princeton University Press.

Burt, Austin, and Robert Trivers. 2006. Genes in Conflict: The Biology of Selfish Genetic Elements. Harvard University Press.

Dawkins, R. 1976. The Selfish Gene Oxford University Press. Oxford University Press. . 1990. "Parasites, Desiderata Lists and the Paradox of the Organism." Parasitology 100: 63-73.

Dawkins, Richard. 1982. The Extended Phenotype: The Long Reach of the Gene. Oxford University Press.

- 2015. Brief Candle in the Dark: My Life in Science. Random House.

Dennett, Daniel Clement. 1995. Darwin's Dangerous Idea: Evolution and the Meanings of Life. Simon \& Schuster.

Edwards, A. W. F. 2014. "R.A. Fisher's Gene-Centred View of Evolution and the Fundamental Theorem of Natural Selection." Biological Reviews of the Cambridge Philosophical Society 89 (1): 135-47.

Ewens, Warren J. 2010. "What Is the Gene Trying to Do?" The British Journal for the Philosophy of Science 62 (1). Oxford University Press: 155-76.

Fisher, R. A. 1930. The Genetical Theory of Natural Selection. OUP Oxford.

Frank, S. A. 2012. "Natural Selection. IV. The Price Equation." Journal of Evolutionary Biology 25 (6): 1002-19.

Gardner, A., and A. Grafen. 2009. "Capturing the Superorganism: A Formal Theory of Group Adaptation." Journal of Evolutionary Biology 22 (4): 659-71.

Gardner, Andy. 2009. “Adaptation as Organism Design.” Biology Letters 5 (6): 861-64.

- 2011. "Kin Selection under Blending Inheritance." Journal of Theoretical Biology 284 (1): $125-29$.

Gardner, A., S. A. West, and G. Wild. 2011. "The Genetical Theory of Kin Selection." Journal of Evolutionary Biology 24 (5): 1020-43.

Godfrey-Smith, Peter. 2009. Darwinian Populations and Natural Selection. Oxford 
University Press.

Grafen, A. 2007. "The Formal Darwinism Project: A Mid-term Report.” Journal of Evolutionary Biology 20 (4): 1243-54.

Grafen, Alan. 2014. "The Formal Darwinism Project in Outline." Biology \& Philosophy 29 (2): 155-74.

Haig, David. 2014. "Genetic Dissent and Individual Compromise." Biology \& Philosophy 29 (2): 233-39.

Hamilton, W. D. 1963. “The Evolution of Altruistic Behavior.” The American Naturalist 97 (896): 354-56.

- 1964. "The Genetical Evolution of Social Behaviour. I and II.” Journal of Theoretical Biology 7 (1): 1-52.

- 1972. "Altruism and Related Phenomena, Mainly in Social Insects." Annual Review of Ecology and Systematics 3: 193-232.

-1977. “"The Selfish Gene.” Nature 267: 102.

Hamilton, William D. 1996. Narrow Roads of Gene Land: Volume 1: Evolution of Social Behaviour. Oxford University Press.

Hawking, Stephen, and Leonard Mlodinow. 2010. "The Grand Design: New Answers to the Ultimate Question of Life." Bantam Books.

Horgan, John. 2015. "Nobel Laureate Steven Weinberg Still Dreams of Final Theory." Scientific American Blog Network. 2015.

https://blogs.scientificamerican.com/cross-check/nobel-laureate-steven-weinberg-still-dr eams-of-final-theory/.

Johnston, Chris. 2014. "Biological Warfare Flares up Again between EO Wilson and Richard Dawkins." The Guardian, November 7, 2014.

http://www.theguardian.com/science/2014/nov/07/richard-dawkins-labelled-journalist-b y-eo-wilson.

Kerr, Benjamin, and Peter Godfrey-Smith. 2002. "Individualist and Multi-Level Perspectives on Selection in Structured Populations." Biology and Philosophy 17 (4): 477-517.

Kohn, Marek. 2004. A Reason for Everything: Natural Selection and the English Imagination. Faber \& Faber.

Krauss, Lawrence M. 2012a. "The Consolation of Philosophy." Scientific American 27. - 2012b. A Universe From Nothing. Simon and Schuster.

Lande, Russell, and Stevan J. Arnold. 1983. "The Measurment Selection on Correlated Characters.” Evolution 37 (6): 1210-26.

Lewontin, R. C. 1977. “"The Selfish Gene.” Nature 267. Nature Publishing Group: 202.

Lloyd, Elisabeth Anne. 1988. The Structure and Confirmation of Evolutionary Theory. Greenwood Press.

Marshall, James A. R. 2015. Social Evolution and Inclusive Fitness Theory: An Introduction. Princeton University Press.

Marshall, Richard. 2016. "From A Biological Point Of View, and Then Some." 3:AM Magazine. October 9, 2016. http://www.3ammagazine.com/3am/biological-point-view/.

Martin A. Nowak, Corina E. Tarnita, Edward O. Wilson. 2011. "A Brief Statement about Inclusive Fitness and Eusociality."

http://ped.fas.harvard.edu/files/ped/files/inclusivefitness_statement_1_0.pdf.

Maynard Smith, J. 1987. "How to Model Evolution." In The Latest on the Best: Essays on Evolution and Optimality, edited by John Dupré, 119-31. MIT Press.

Maynard Smith, John. 1975. "Survival through Suicide." New Scientist , 496.

- 1997 Interview by Richard Dawkins. Web of Stories. 
https://www.webofstories.com/play/john.maynard.smith/40.

- 2002. "Commentary on Kerr and Godfrey-Smith." Biology and Philosophy 17 (4): $523-27$.

Maynard Smith, John, and Eörs Szathmáry. 1995. The Major Transitions in Evolution. Oxford University Press.

Nowak, Martin A., Corina E. Tarnita, and Edward O. Wilson. 2010. "The Evolution of Eusociality." Nature 466 (7310): 1057-62.

Okasha, Samir. 2006. Evolution and the Levels of Selection. Clarendon Press.

- 2008. "Fisher's Fundamental Theorem of Natural Selection-A Philosophical Analysis." The British Journal for the Philosophy of Science 59 (3). Oxford University Press: $319-51$.

Pradeu, Thomas. 2017. "Thirty Years of Biology \& Philosophy: Philosophy of Which Biology?" Biology \& Philosophy 32 (2): 149-67.

Price, G. R. 1970. "Selection and Covariance.” Nature 227 (5257): 520-21.

Queller, David C. 1992. “A General Model for Kin Selection.” Evolution 46 (2): 376-80.

Schilpp, Paul Arthur. 2001. Albert Einstein: Philosopher-Scientist. Fine Communications.

Segerstrale, Ullica. 2013. Nature's Oracle: The Life and Work of W.D. Hamilton. Oxford University Press.

Servedio, Maria R., Yaniv Brandvain, Sumit Dhole, Courtney L. Fitzpatrick, Emma E. Goldberg, Caitlin A. Stern, Jeremy Van Cleve, and D. Justin Yeh. 2014. "Not Just a Theory-The Utility of Mathematical Models in Evolutionary Biology." PLoS Biology 12 (12). Public Library of Science: e1002017.

Sober, Elliott. 1984. The Nature of Selection: Evolutionary Theory in Philosophical Focus. MIT Press.

Taylor, Peter D., and Steven A. Frank. 1996. "How to Make a Kin Selection Model." Journal of Theoretical Biology 180 (1): 27-37.

Veelen, Matthijs van, Benjamin Allen, Moshe Hoffman, Burton Simon, and Carl Veller. 2017. "Hamilton's Rule." Journal of Theoretical Biology 414: 176-230.

West, Stuart A., and Andy Gardner. 2013. "Adaptation and Inclusive Fitness." Current Biology 23 (13): R577-84.

Wild, Geoff, and Arne Traulsen. 2007. "The Different Limits of Weak Selection and the Evolutionary Dynamics of Finite Populations." Journal of Theoretical Biology 247 (2): 382-90.

Williams, George C. 1966. Adaptation and Natural Selection: A Critique of Some Current Evolutionary Thought. Princeton University Press.

Wimsatt, William C. 1970. "Adaptation and Natural Selection: A Critique of Some Current Evolutionary Thought." Philosophy of Science 37 (4): 620-23.

Zuk, Marlene. 2000. "Noted Biologist Bill Hamilton Dies.” Evolution 54 (3): 1075-76. 


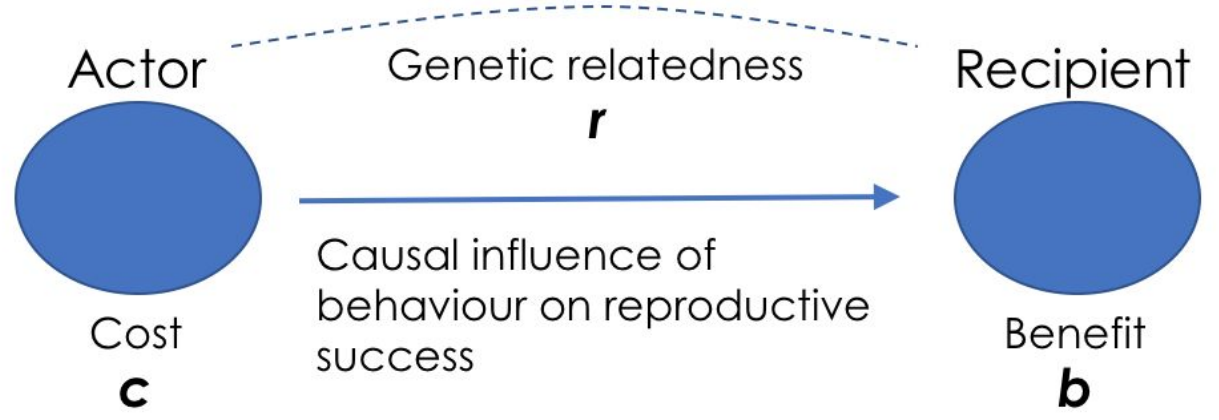

Figure 1 Hamilton's Rule in its simplest form. Hamilton's Rule says that a costly social behaviour can evolve if and only if $r b>c$, where $r$ is the coefficient of relatedness between the actor and the recipient, $b$ is the fitness benefit to the recipient of the social behaviour, and $c$ is the fitness cost to the actor. Adopted from Figure 2.1 in Birch (2017).

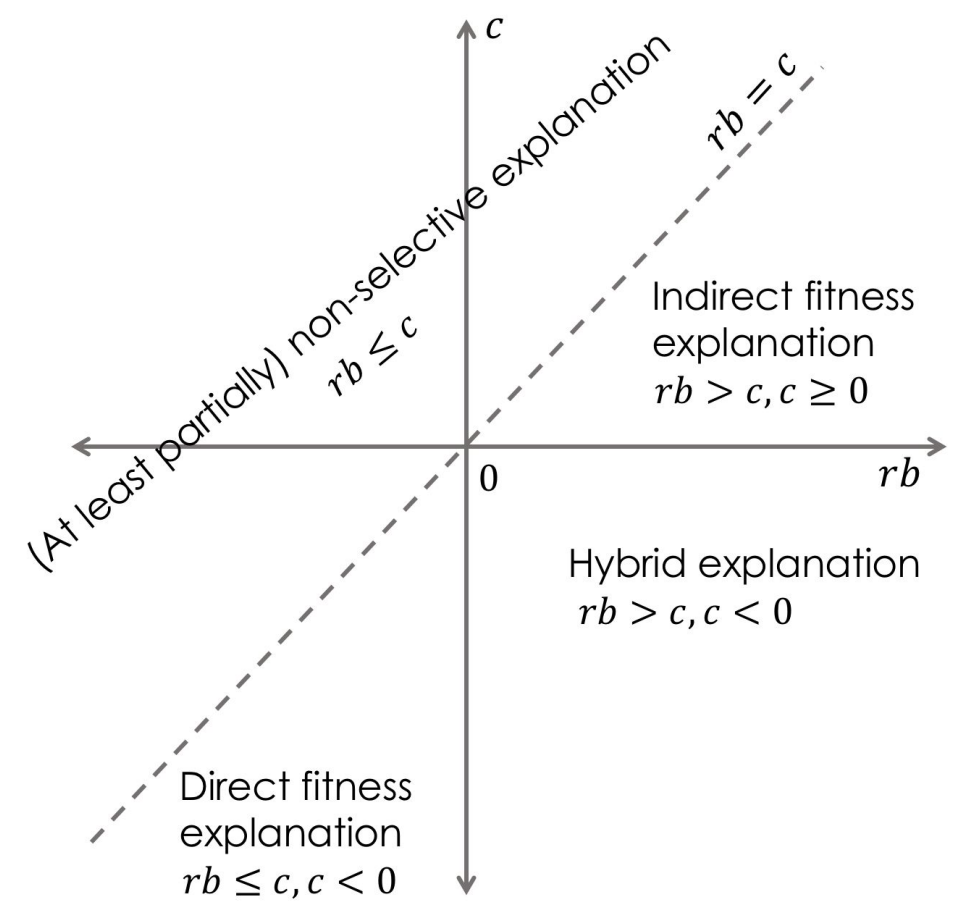

Figure 2 The space of explanation is key to HRG as an organizing framework under which more detailed models can be compared and contrasted. HRG classifies models of social evolution into four categories, depending on the relationship between $r b$ and $c$. Direct fitness is based on personal offspring production of an actor and indirect fitness on the actor's social influence on the offspring production of others. All explanations of a positive change fall somewhere in this space. Adopted from Figure 2.2 in Birch (2017). 